\title{
The Effects of Disinfectants on Dimensional Accuracy and Surface Quality of Impression Materials and Gypsum Casts
}

\author{
Wala M. Amin' ${ }^{\mathrm{a}, \mathrm{g}}$, Muna H. Al-Ali ${ }^{\mathrm{b}}$, Sandra K. Al Tarawneh ${ }^{\mathrm{c}}$, Sahar Th. Taha ${ }^{\mathrm{d}}$, \\ Mohamed W. Saleh ${ }^{\mathrm{e}}$, Nadia Ereifij ${ }^{\mathrm{f}}$
}

\begin{abstract}
Background: The study aimed to evaluating the effect of disinfecting impression materials on the dimensional accuracy and surface quality of the resulting casts.

Methods: Impressions of a steel die constructed according to ANSI/ADA specification No.18 were made with each of alginate, addition cured silicone, condensation cured silicone and zinc oxide eugenol paste, and disinfected consequently by each of $0.2 \%$ chlorhexidine gluconate, $1 \%$ sodium hypochlorite, $2 \%$ gluteraldehyde for 5 minutes, and $0.5 \%$ sodium hypochlorite for 10 minutes. Dimensions of the disinfected impressions and their resultant casts were measured using a computerized digital caliper, and the dimensional changes were calculated. Reproduction of detail and surface quality of the resultant casts were assessed by grading casts surfaces according to a specific scoring system.
\end{abstract}

Results: The $0.5 \%$ sodium hypochlorite was found to produce the least dimensional changes in all the impression materials. Corsodyl produced the maximum changes in both alginate and zinc-oxide eugenol while addition-cured silicon was most affected by Gluteraldehyde and condensation-cured silicon was most affected by Hexana. The dimensional changes, however, were minimal and clinically insignificant. Addition-cured silicon showed the best surface quality and dimensional stability followed by condensation-cured sili-

\footnotetext{
Manuscript accepted for publication April 24, 2009.

aDepartment of Prosthetic Dentistry, Faculty of Dentistry, University of Jordan, P.O. Box 13455, Amman 11942, Jordan

${ }^{b}$ Faculty of Dentistry, University of Melbourne, Australia

'Faculty of Dentistry, University of North Carolina, USA

${ }^{\mathrm{d}}$ Faculty of Dentistry, University of Michigan, USA

'Research fellow and Clinical Dental Practitioner, Private practice, Amman, Jordan

fDepartment of Prosthetic Dentistry, Faculty of Dentistry, University of Jordan, Jordan

gCorresponding author: profwala@gmail.com
}

doi:10.4021/jocmr2009.04.1235 con. Alginate and zinc-oxide eugenol had poorer surface quality and were affected to a higher extent by the disinfection procedures.

Conclusions: The results were comparable with the standard specifications for dimensional stability. Recommendations were made for the use of 10 minutes immersion in $0.5 \%$ sodium hypochlorite as the most appropriate disinfection protocol to the investigated impression materials.

Keywords: Disinfectants; Gypsum casts; Impressions; Alginate; Addition-cured silicone; Sodium hypochlorite

\section{Introduction}

Contamination of dental impressions with saliva and blood from the oral cavity occurs readily in dental clinics. Direct interaction between dental clinics and dental laboratories makes contaminated dental impressions difficult items to deal with from the cross infection point of view. Previous reports indicated that contaminated impressions can crossinfect gypsum casts that were poured against them [1]. Until 1991, rinsing impressions under running water was the recommended practice [2]. Guidelines for infection control in dental health care suggested that all dental prostheses and prosthodontic items should be cleaned, disinfected, and rinsed before they are handled in the laboratory using an active hospital disinfectant $[3,4]$.

Many studies have evaluated the effect of various disinfectants and methods of disinfecting impression materials, but the results of those studies varied widely. The role of a disinfectant should, ideally, be of a dual purpose, it must be an effective antimicrobial agent, yet cause no adverse response to the dimensional accuracy and surface features of the impression material and the resultant gypsum cast [5].

The dimensional stability of disinfected impressions had been a subject of investigation by many researchers who used a variety of approaches. Some studies used full arch casts [6-8] while others studied the effects on a die [8]. The measuring technique used in determining dimensional changes after disinfection also varied from using a Boley 
gauge [6], to the use of measuring microscope [9].

Therefore, the aim of the present investigation was to examine the effect of several disinfecting solutions on four commonly used impression materials. The objectives to achieve this aim were: (1) To assess the dimensional accuracy and surface quality of the impressions and the resultant gypsum casts using a purpose-made computerized digital caliper of high sensitivity (accurate to $0.001 \mathrm{~mm}$ ); (2) To compare the results with the standard specifications; (3) To recommend, accordingly, a disinfection protocol for the corresponding impression materials.

The null hypothesis tested was that the different types of disinfectants used would produce similar effects on the dimensional accuracy and surface quality of the various impression materials evaluated and the resultant casts.

\section{Materials and Methods}

The impression materials and disinfectants employed in this study were chosen to represent the most commonly used by dentists in Jordan (Tables 1 and 2).

A stainless steel test die, an impression mould, a riser, and a gypsum mould were constructed according to ANSI/ ADA specification No.18 [10] and BSI 12:1999 [11]. These are shown in Figure 1.

Impression materials were mixed according to manufacturers' instructions, the impression mould was placed on the die and a freshly mixed homogenous impression material was placed in the center of the die and spread to fill the mould. A flat plastic plate was placed over the mould and pressed the impression material firmly against the die assuring a positive metal to metal contact between the mould and the die. A metal flat weight of $1 \mathrm{Kg}$ simulating the operator's finger pressure on a tray was placed over the plastic plate and the whole assembly was transferred into a water bath which was kept at $35^{\circ} \mathrm{C} \pm 1$ simulating the mouth temperature [12].

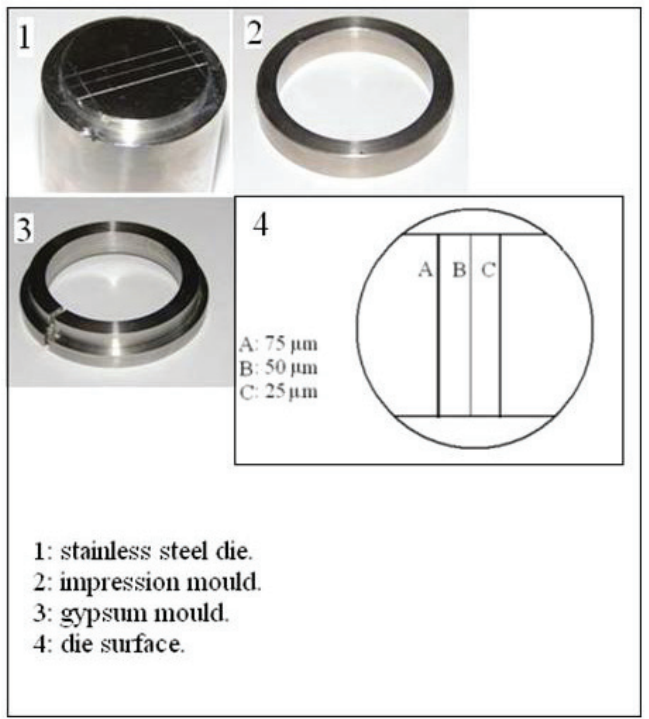

Figure 1. The parts " $1,2,3$ " of the assembly constructed according to the ADA specification number 18 for testing dimensional stability and reproduction of details of impression materials. The diagram " 4 " representing the surface of the die showing the three vertical lines.

After the impression material had set, the assembly was removed from the water bath and the impression with the mould separated from the die. The test die and the mould were cleaned, dried and made ready for the next impression. After separation of the impression/mould assembly from the die, a riser was used to push the impression up to the same level of the surface of the mould.

Each impression surface was scanned prior to its disinfection using a two-dimensional computer scanner (BenQ scanner 2005) at a resolution of 500 Pixels/inch. The impression was then immersed in the disinfecting solution for the recommended time followed by rinsing in tap water at room

Table 1. Impression materials and their recommended setting times

\begin{tabular}{lllc}
\hline Impression material & Brand name /Supplier & Batch Number & $\begin{array}{l}\text { Recommended } \\
\text { setting time }\end{array}$ \\
\hline Alginate & Alginoplast ${ }^{\circledR}$ fast set/Heraeus Kulzer/Holland & 2557591 & 2 min \\
Add. Silicone & $\begin{array}{l}\text { Elite H-D }{ }^{+} / \text {Zhermack } \\
\text { Badia Polesine (Rovigo) Italy }\end{array}$ & C203035 & 8 min \\
Cond. Silicone & $\begin{array}{l}\text { Bonasil light } \\
\text { DMP LTD , E.U. }\end{array}$ & 82350305 & 8 min \\
Zinc Oxide -Eugenol & SS White Group/England & 34930604 & 5 min
\end{tabular}


Table 2. The employed disinfectants and their recommended immersion times.

\begin{tabular}{|c|c|c|c|c|}
\hline Disinfectant & Brand name/ Supplier & Conc. & $\begin{array}{l}\text { Batch } \\
\text { Number }\end{array}$ & $\begin{array}{l}\text { Recommended } \\
\text { immersion time }\end{array}$ \\
\hline $\begin{array}{l}\text { Chlorhexidine } \\
\text { gluconate }\end{array}$ & $\begin{array}{l}\text { Hexana/ M.H. Sider Health Care } \\
\text { Prep./Jordan }\end{array}$ & $0.2 \%$ & Н 0142 & $5 \mathrm{~min}$ \\
\hline $\begin{array}{l}\text { Chlorhexidine } \\
\text { gluconate }\end{array}$ & Corsodyl/ Glaxo Smith Kline/UK & $0.2 \%$ & $335 \mathrm{E}$ & $5 \min$ \\
\hline $\begin{array}{l}\text { Sodium } \\
\text { Hypochlorite }\end{array}$ & $\begin{array}{l}\text { Hypex/ Jordan Chemical Industries } \\
\text { Co. Ltd/Jordan }\end{array}$ & $1.0 \%$ & & $5 \mathrm{~min}$ \\
\hline $\begin{array}{l}\text { Sodium } \\
\text { Hypochlorite }\end{array}$ & $\begin{array}{l}\text { Hypex/Jordan Chemical Industries } \\
\text { Co.Ltd/Jordan }\end{array}$ & $0.5 \%$ & & $10 \mathrm{~min}$ \\
\hline Gluteraldehyde & $\begin{array}{l}\text { Eimaldehyde solution Al-Eiman for } \\
\text { cosmetics/ Jordan }\end{array}$ & $2.2 \%$ & 05090947 & $5 \mathrm{~min}$ \\
\hline
\end{tabular}

temperature for $10 \mathrm{~s}$. Twenty five impressions were made with each impression material, five impressions of each material for each of the five disinfectants. Additional five impressions of each material were immersed in sterile water for five minutes and used as control. Each impression was dried after rinsing with water and scanned in the same manner.

All impressions were poured within $1 \mathrm{~h}$ after disinfection (the alginate impressions were kept in a sealed bag at $100 \%$ humidity) using dental stone (Elite $®$ Dental Stone / Zhermack, type IV framework dental stone) which was first wetted manually and then mixed on a vibrator for $30 \mathrm{~s}$. Two hours after pouring the impressions, they were separated, and the resultant casts were coded and scanned at a resolution of $500 \mathrm{Pixel} / \mathrm{inch}$.

\section{Dimensional Stability}

Measurements were made by one operator using a computerized digital calipers (C.D.C) tool that measured the distance between any two given points on a scanned image of an impression or a cast by counting the pixels between the two points on the scanned image of the impression/cast, and

Table 3. The mean dimensional change for each impression material / disinfectant combination illustrating the dimensional change between the stone cast and the original die

\begin{tabular}{lllll}
\hline Disinfectant & $\begin{array}{l}\text { Alginate } \\
(\mathbf{m m}) \times \mathbf{1 0}^{-3}\end{array}$ & $\begin{array}{l}\text { Addition Silicone } \\
(\mathbf{m m}) \times \mathbf{1 0}^{-3}\end{array}$ & $\begin{array}{l}\text { Condensation Silicone } \\
(\mathbf{m m}) \times \mathbf{1 0}^{-3}\end{array}$ & $\begin{array}{l}\text { Zinc Oxide Eugenol } \\
(\mathbf{m m}) \times \mathbf{1 0}^{-3}\end{array}$ \\
\hline Hexana & 7.1 & -3.9 & 4.7 & -1.5 \\
Corsodyl & 10.8 & -5 & 4 & -5 \\
Sterile water & 3.8 & -3 & -3 & -8 \\
$\begin{array}{l}1 \% \text { Na-Hypochlorite } \\
\text { 0.5\% Na- }\end{array}$ & 4.8 & -5.8 & -2 & -1.1 \\
Hypochlorite & 2.3 & -2.4 & 0.6 & -2.1 \\
Gluteraldehyde & 3 & -8 & 1.2 & -2.5 \\
\hline
\end{tabular}




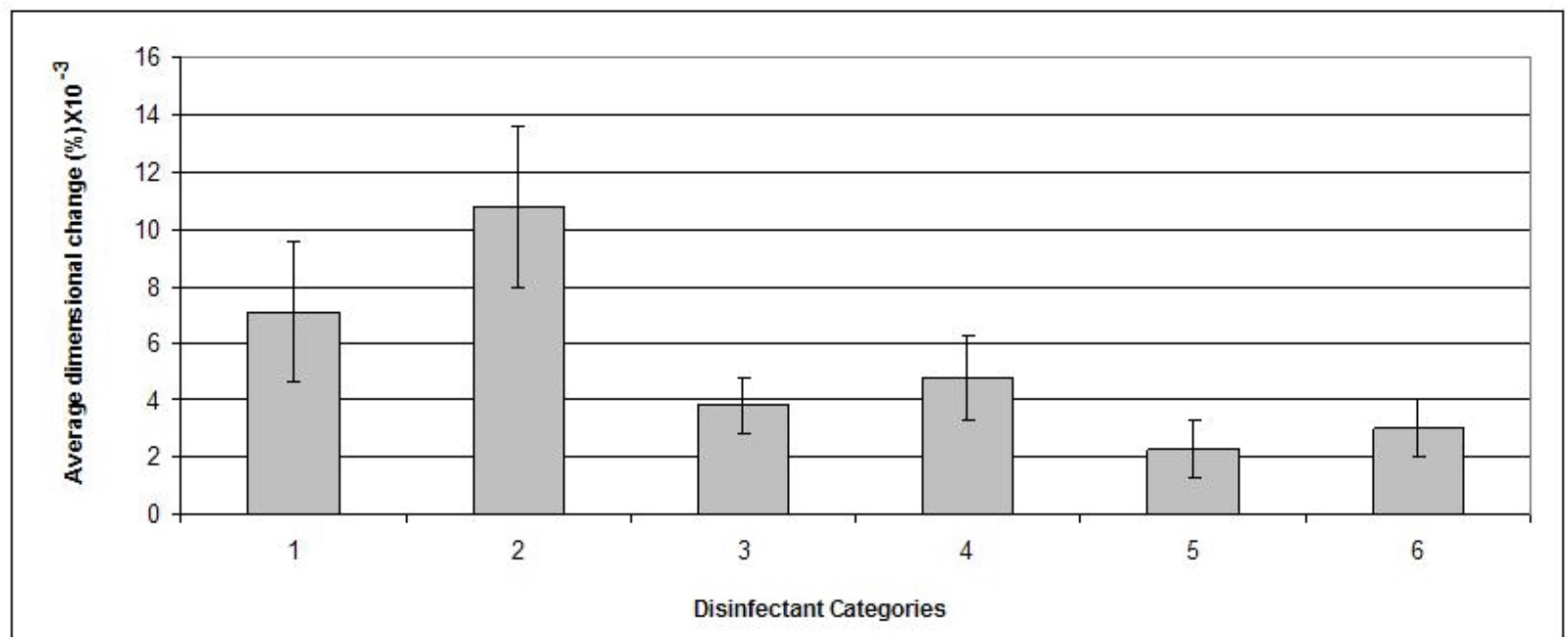

Figure 2. Dimensional changes for casts made from alginate impression material after disinfection.

calculated the distance in millimeters [13]. Measurements were made between the cross lines, shown in Figure 1. Three readings were made for each stone cast: the first reading was for line " $\mathrm{A}$ ", the second for line "B" and the third for line "C". The mean of the readings was taken for each cast and the dimensional change was calculated by using the following formula: (L - L'/ L) X 100, where L represents the dimensions of the die, and L' represents the mean dimension of the experimental cast (control or after disinfection).

Data sets were treated statistically using analysis of variance (ANOVA) at 95\% level of confidence and Fisher's Least Significant Difference for multiple comparisons.

\section{Surface quality}

\section{Detail reproduction of impressions}

Impression were inspected visually without magnification and the accepted impressions were those that passed the ANSI/ADA specification for detail production which reproduced the full length of the $50 \mu \mathrm{m}$-wide line for the alginate ,and the full length of the $25 \mu \mathrm{m}$-wide line for the Zinc Oxide Eugenol and both the addition and condensation cured silicone impression materials.

\section{Detail reproduction of stone casts}

For assessment of detail reproduction of stone casts, the scanned images of the casts were inspected at X10 magnification and the following scoring system [12] with rating values from one to four was used as following: Rating 1: Well-defined, sharp detail and continuous line; Rating 2: Continuous line but with some loss of sharpness; Rating 3: Poor detail or loss of continuity of line; Rating 4: Marginally or completely not discernible line.
According to ANSI/ADA specification No.18 [10] dental stone casts made from alginate specimens have to reproduce the $75 \mu \mathrm{m}$-wide line, and to satisfy specification No.19 [14] casts poured against silicone rubber must reproduce the $25 \mu \mathrm{m}$-wide line.

For grading purposes both the $75 \mu \mathrm{m}$ and $50 \mu \mathrm{m}$-wide lines were assessed for alginate [9] and only the $25 \mu \mathrm{m}$-wide line was evaluated for Zinc Oxide Eugenol and the two silicone materials. Assessment of surface quality and evaluation of the detail reproduction of stone cast were carried out by one operator. The results were subjected to statistical analysed using Kruskal-Wallis test.

\section{Results}

\section{Dimensional stability}

The mean value of the 15 measurements made on the casts, which resulted from pouring disinfected impressions, compared with corresponding measurements made on the steel die and controls are presented in Table 3. Dimensional changes of the casts made by pouring impressions of each material, namely, alginate, addition-cured silicone, condensation-cured silicone and zinc oxide-eugenol are presented graphically in Figures 2, 3, 4 and 5 respectively.

The disinfectant that showed the least detrimental effect on the alginate impression material was $0.5 \%$ sodium hypochlorite which demonstrated as little dimensional change as $0.0023 \%$ and resulted in a cast with significantly improved dimensions $(p<0.05)$ compared to that of the water control (the cast which resulted by pouring an alginate impression after 10 min immersion in distilled water). "Corsodyl", on 


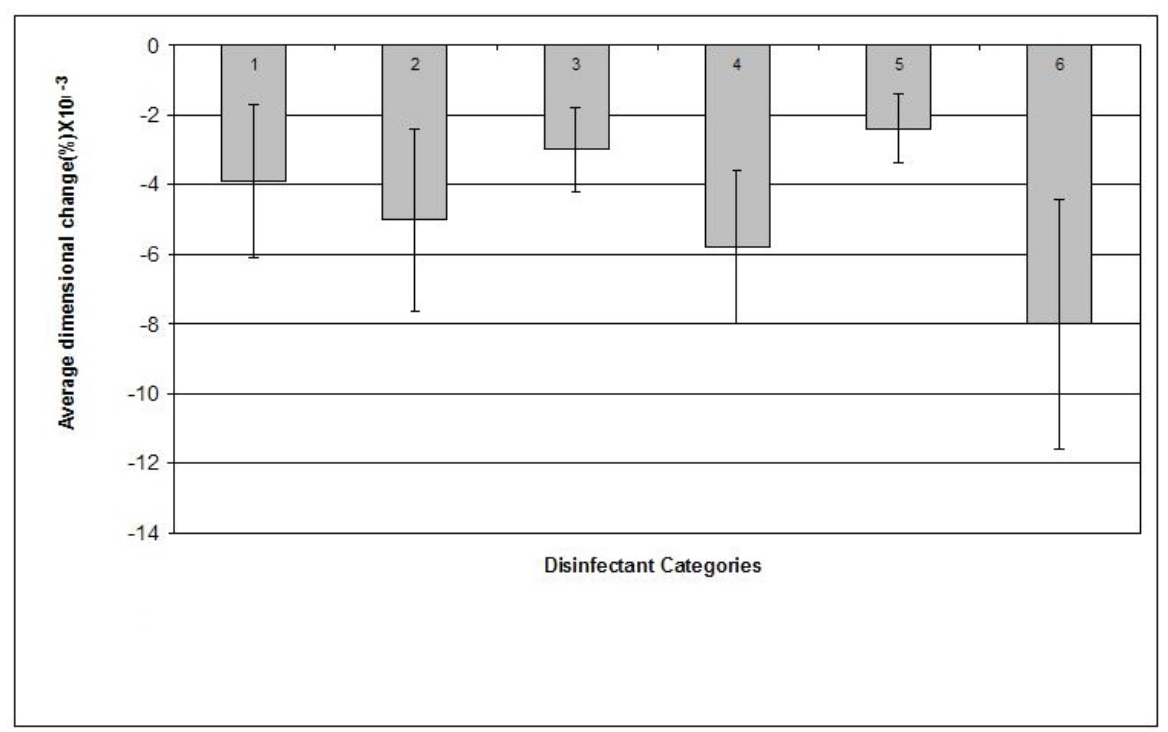

Figure 3. Dimensional changes for casts made from addition silicone impression material after disinfection.

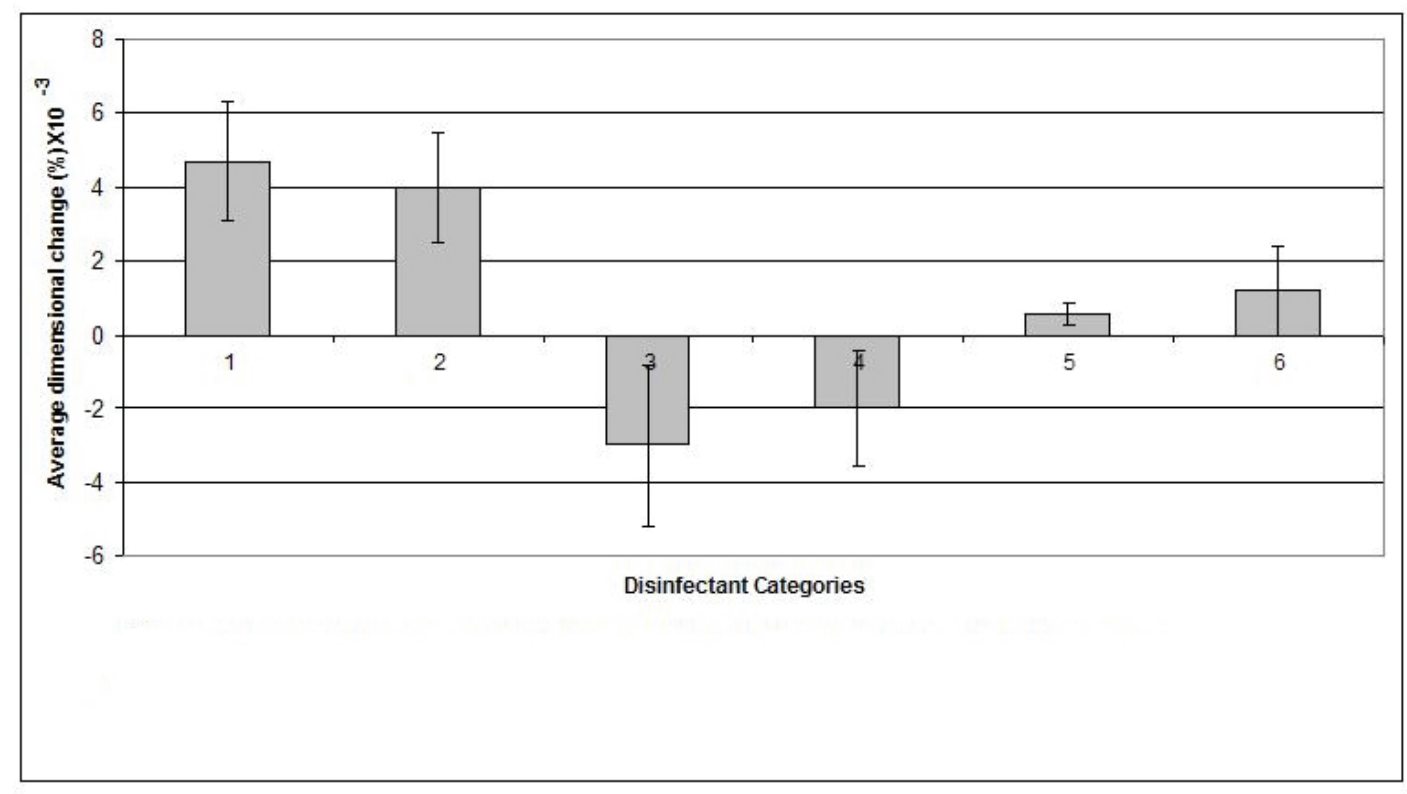

Figure 4. Dimensional changes for casts made from condensation silicone impression material after disinfection.

the other hand, was the disinfectant that caused the largest dimensional changes in alginate and incurred $0.108 \%$ swelling of the alginate impression.

Similar to its effect on alginate, sodium hypochlorite $0.5 \%$ disinfectant caused the smallest dimensional change $(0.0024 \%)$ in the addition-cured silicone impression material and showed some improvement, although not significant, in the dimensions of the resultant casts compared to that of the water control. On the other hand, Gluteraldehyde caused the biggest change $(0.008 \%)$ in the material's dimensions.

The condensation-cured silicone impression material demonstrated the least dimensional change $(0.0006 \%)$ when disinfected by $0.5 \%$ sodium hypochlorite that showed a significant improvement $(\mathrm{p}<0.05)$ in cast dimensions over the cast of the water control, whereas, Hexana disinfectant caused the largest dimensional change $(0.0012 \%)$ in this impression material.

The zinc oxide-eugenol impression material showed a 


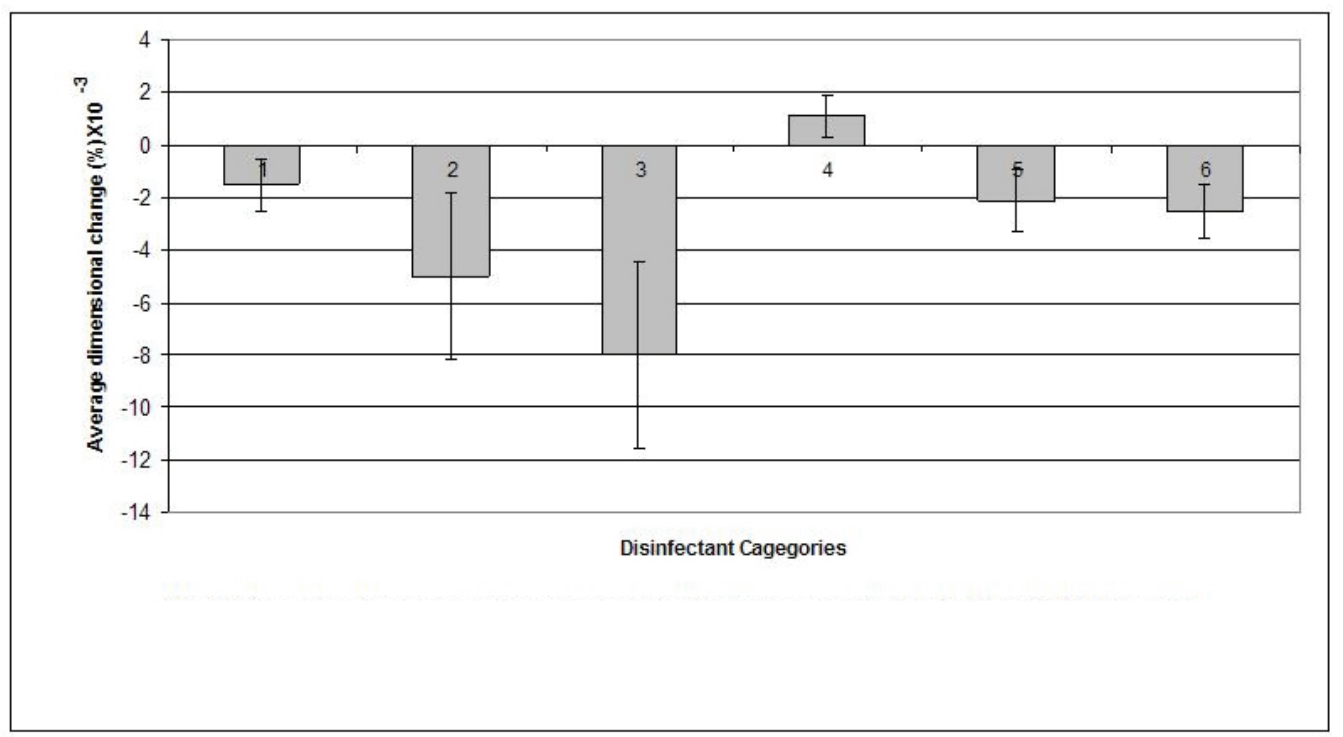

Figure 5. Dimensional changes for casts made from Zinc Oxide Eugenol impression materials after disinfection.

minimum dimensional change $(0.0011 \%)$ following disinfection by $1 \%$ sodium hypochlorite and a maximum change in dimension $(0.005 \%)$ after disinfection by "Corsodyl".

\section{Surface quality}

The results of evaluating the effect of the disinfectants on the surface integrity of the stone casts revealed that $70 \%$ of the casts were grade $1 ; 19.2 \%$ grade 2 and $10.8 \%$ demonstrated grade 3 surface quality. None of the examined casts showed grade 4 surface. These results are illustrated in Figure 6 .

The majority of the casts that showed grade 1 surface were those made from pouring addition-cured silicone impression material (36.5\%), followed by those resulted from pouring condensation-cured silicone impressions (32.4\%); and those resulted from pouring alginate impressions $(23 \%)$, whereas only $8.1 \%$ of grade 1 surface quality impressions were demonstrated by casts made from pouring disinfected zinc oxide-eugenol impressions.

Grade 2 quality surfaces were mostly of casts that resulted from pouring disinfected alginate and zinc oxideeugenol impressions (34.8\% each) and partly of casts resulted from pouring condensation-cured silicone impressions $(17.4 \%)$ and addition-cured silicone impressions (13\%).

The casts that showed grade 3 surface quality were mostly those poured from zinc oxide-eugenol impressions (46.2\%) followed by those made by pouring alginate impressions $(38.4 \%)$. The condensation-cured silicone impressions produced casts that formed $15.4 \%$ of grade 3 surface quality casts; whereas none of the casts that resulted from pouring the addition-cured silicone impression were rated as grade 3 quality surfaces.

\section{Discussion}

\section{Dimensional changes of the stone casts}

None of the disinfectants had a discernable adverse effect on the accuracy of the resultant casts. In fact, some disinfectants such as $0.5 \%$ sodium hypochlorite significantly improved the dimensions of the resultant casts. This has confirmed the findings of some of the previous studies $[5,9$, 15], while it contrasted with other studies that demonstrated adverse effects of elastomer immersion in disinfecting solutions [16].

Stone casts resulted from pouring decontaminated alginate impressions using the employed disinfectants showed slight dimensional shrinkage. This may be attributed to the processes of syneresis and imbibitions to which alginate was subjected. Alginate impressions were kept in a humid atmosphere for $1 \mathrm{~h}$ prior to pouring the stone casts, during which the material might have been subjected to syneresis which caused shrinkage of the impression, but upon pouring the impressions with stone, the alginate imbibed the moisture of the stone mix which caused swelling of the impression and partly compensated for the syneresis shrinkage. Of all the disinfectants employed for decontaminating alginate impressions, sodium hypochlorite $0.5 \%$ affected the least changes in the dimensions of the resultant casts. This disinfectant, in fact, improved cast dimensions compared to those of the wa- 


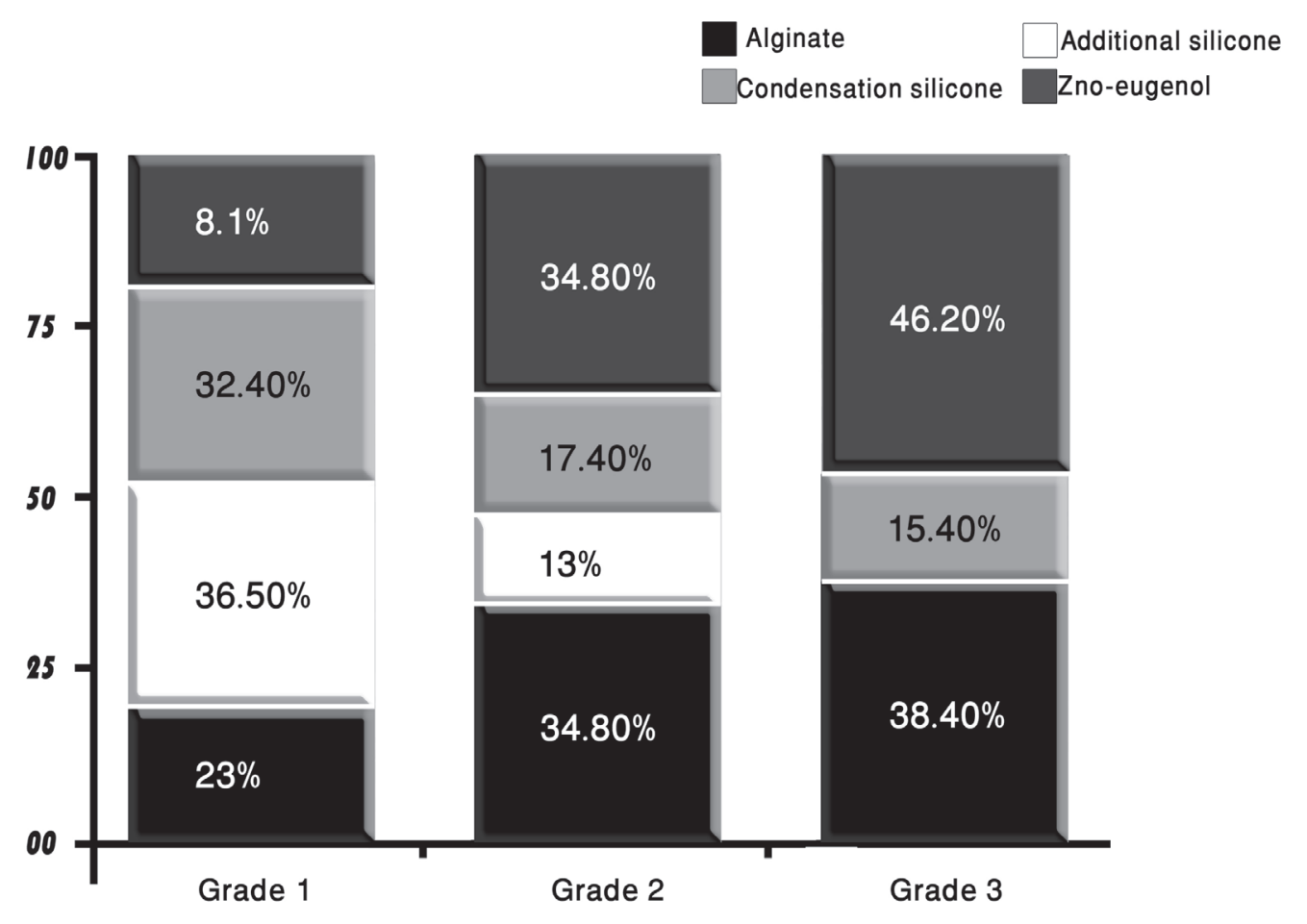

Figure 6. The distribution of impression materials according to their surface quality grades scored after disinfection.

ter control. These findings were consistent with the previous studies which reported that no significant distortion of alginate impressions could result from decontaminating these impressions by a variety of disinfectants [7, 17].

Stone casts that resulted by pouring disinfected addition-cured silicone impressions demonstrated a minimal reduction in dimensions caused by a marginal swelling of the impressions. Compared to the other impression materials investigated in this study, addition-cured silicone demonstrated superior dimensional stability. The changes in the dimensions of the resultant casts produced by pouring disinfected addition-cured silicone impressions were extremely minimal, clinically insignificant and within the range of changes that is acceptable by the standard specifications [14]. Once again, sodium hypochlorite $0.5 \%$ disinfectant affected some improvement in the dimensions of the casts that resulted by pouring addition-cured silicone impressions compared to the casts of the water control.

The stone casts poured from condensation-cured silicone impressions that were disinfected by each of: sodium hypochlorite $0.5 \%$, gluteraldehyde, Corsodyl and Hexana demonstrated slight expansion as a result of shrinkage that took place in the condensation-cured silicone impression material upon disinfection. Whereas, casts produced by pouring the condensation-cured silicone impressions following disinfection by $1 \%$ sodium hypochlorite displayed a marginal reduction in dimensions as a result of swelling of the impression material upon exposure to $1 \%$ sodium hypochlorite. These differences may be attributed to the nature of the setting reaction of the condensation-cure silicone rather than to the disinfectant itself. This is consistent with previous studies [18-21] which pointed that care should be taken when working with condensation-cured silicone impression which may uncontrollably contract due to the loss of byproducts. Similar to the other investigated impression materials, the condensation-cured silicone produced stone casts that exhibited minimal dimensional changes when the impressions were disinfected by $0.5 \%$ sodium hypochlorite. These casts were closer in dimensions to the steel die than were the water control casts.

Casts produced by pouring disinfected zinc oxide-eugenol impressions demonstrated slight reduction in dimensions caused by marginal swelling of zinc oxide-eugenol impression upon exposure to the disinfectants except to $1 \%$ sodium hypochlorite which affected a minimal and clinically insignificant expansion of the resultant casts.

To this end, the observed differences in the behavior of the impression materials when exposed to disinfectants which affected some changes in the dimensions of the resultant casts may be attributed partly to the different characteristics of the impression materials themselves, and partly to the different disinfection regimens used. 


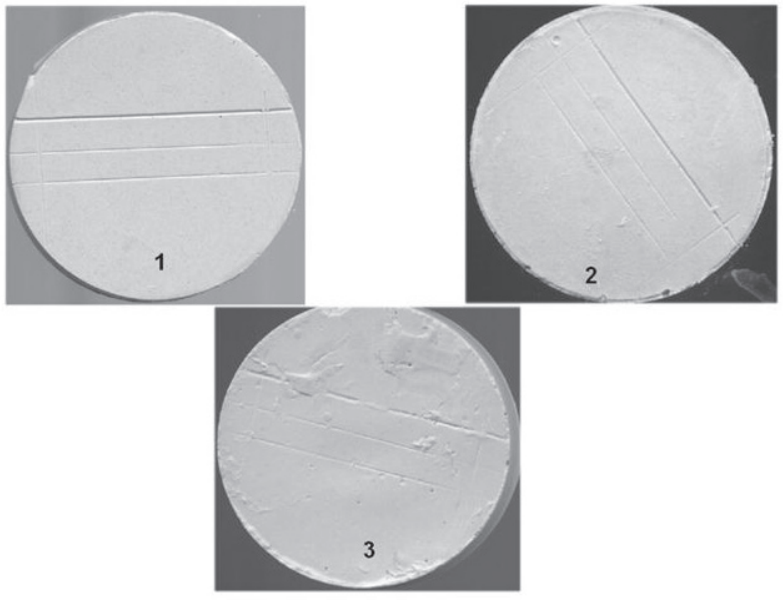

Figure 7. Surface quality and detail reproduction (X10 magnification): 1- sharp detail, continuous line; 2- continuous lines but with some loss of sharpness; 3- rough appearance with loss of continuity of the line.

\section{Surface quality}

The effect of disinfectants on the surface quality of impressions indicated that the silicones, both addition and condensation-cured types, were superior in terms of surface integrity to the other impression materials. This is due to the hydrophobic nature of silicones which made the surface of these impressions highly resistant to the attack by the aqueous disinfectants regardless of their types or the length of exposure period. On the other hand, alginate impression material imbibed the disinfectants which, in turn, inflicted a discernable damage to the alginate impression surface.

Similar surface effects were displayed by zinc oxideeugenol impressions which in spite of the oily nature of its surface, the tested disinfectants seemed to have attacked the impression surface chemically and inflicted a noticeable damage. The extent of this damage was proportionally related to the concentration of the disinfectant and the length of exposure of the impression to the disinfectant.

\section{Summary}

In the light of the findings of the present investigation, the following conclusions can be obtained: (1) The five disinfectants employed in the present study affected all four impression materials very marginally and the stone casts obtained from disinfected impressions showed minimal dimensional changes that can be considered clinically insignificant. (2) Silicone impression materials of the two types, addition-cured and condensation-cured types, displayed su- perior qualities in terms of dimensional stability and surface integrity over alginate and zinc oxide-eugenol impression materials. The latter two materials, although showed minimal changes in dimensions, but were less stable compared to the silicones. (3) Stone casts obtained from alginate and zinc oxide-eugenol impression materials were of comparable dimensional stability and surface quality following each of the disinfection procedures. (4) Decontaminated addition-cured silicone impressions using all the employed disinfectants produced stone casts with dimensions very closely comparable to those of the standard metal die. (5) Of all the disinfectants employed in the present investigation, $0.5 \%$ sodium hypochlorite affected the least changes in the dimensions of the four impression materials and had a negligible effect on the quality of the materials' surface. The use of $0.5 \%$ sodium hypochlorite can, therefore, be recommended for disinfection by 10-minutes immersion of alginate; zinc oxide-eugenol; addition-cured silicone and condensation-cured silicone impressions prior to transporting these impressions to the laboratory.

\section{Acknowledgements} this article.

The authors declare no conflicts of interest related to

\section{References}

1. Leung RL, Schonfeld SE. Gypsum casts as a potential source of microbial cross-contamination. J Prosthet Dent 1983;49:210-211.

2. Fabiani L, Mosca G, Giuliani AR. Hygiene in dental practices. Eur J Paediatr Dent 2006;7:93-97.

3. Infection control recommendations for the dental office and the dental laboratory. ADA Council on Scientific Affairs and ADA Council on Dental Practice. J Am Dent Assoc 1996;127:672-680.

4. Kohn WG, Collins AS, Cleveland JL, Harte JA, Eklund KJ, Malvitz DM. Guidelines for infection control in dental health-care settings--2003. MMWR Recomm Rep 2003;52:1-61.

5. Taylor RL, Wright PS, Maryan C. Disinfection procedures: their effect on the dimensional accuracy and surface quality of irreversible hydrocolloid impression materials and gypsum casts. Dent Mater 2002;18:103-110.

6. Merchant VA, McNeight MK, Ciborowski CJ, Molinari JA. Preliminary investigation of a method for disinfection of dental impressions. J Prosthet Dent 1984;52:877879.

7. Herrera SP, Merchant VA. Dimensional stability of dental impressions after immersion disinfection. J Am Dent Assoc 1986;113:419-422. 
8. Palenik CJ, Miller $\mathrm{CH}$. Treating highly infectious patients in the dental office. J Indiana Dent Assoc 1985;64:11-15.

9. al-Omari WM, Jones JC, Wood DJ. The effect of disinfecting alginate and addition cured silicone rubber impression materials on the physical properties of impressions and resultant casts. Eur J Prosthodont Restor Dent 1998;6:103-110.

10. Council adopts American Dental Association Specification no. 18 (alginate impression material). Council on Dental Materials and Devices. J Am Dent Assoc 1968;77:1354-1358.

11. Revised American Dental Association Specification no. 19 for Non-aqueous, Elastomeric Dental Impression Materials. J Am Dent Assoc 1977;94:733-741.

12. Morrow RM, Brown CE, Jr., Stansbury BE, DeLorimier JA, Powell JM, Rudd KD. Compatibility of alginate impression materials and dental stones. J Prosthet Dent 1971;25:556-566.

13. Amin WM, Taha ST, Al-Tarawneh SK, Saleh MW, Ghzawi A. The relationships of the maxillary central incisors and canines to the incisive papilla in Jordanians. $\mathrm{J}$ Contemp Dent Pract 2008;9:42-51.

14. Millman K. Disinfection of impressions. Br Dent J
1995; $179: 328$.

15. Matyas J, Dao N, Caputo AA, Lucatorto FM. Effects of disinfectants on dimensional accuracy of impression materials. J Prosthet Dent 1990;64:25-31.

16. Thouati A, Deveaux E, Iost A, Behin P. Dimensional stability of seven elastomeric impression materials immersed in disinfectants. J Prosthet Dent 1996;76:8-14.

17. Durr DP, Novak EV. Dimensional stability of alginate impressions immersed in disinfecting solutions. ASDC J Dent Child 1987;54:45-48.

18. Lepe X, Johnson GH, Berg JC. Surface characteristics of polyether and addition silicone impression materials after long-term disinfection. J Prosthet Dent 1995;74:181186.

19. Davis BA, Powers JM. Effect of immersion disinfection on properties of impression materials. J Prosthodont 1994;3:31-34.

20. Adabo GL, Zanarotti E, Fonseca RG, Cruz CA. Effect of disinfectant agents on dimensional stability of elastomeric impression materials. J Prosthet Dent 1999;81:621-624.

21. Johansen RE, Stackhouse JA, Jr. Dimensional changes of elastomers during cold sterilization. J Prosthet Dent $1987 ; 57: 233-236$. 